\title{
Microsatellite instable vs stable colon carcinomas: analysis of tumour heterogeneity, inflammation and angiogenesis
}

L De Smedt ${ }^{1}$, J Lemahieu ${ }^{2}$, S Palmans ${ }^{1}$, O Govaere ${ }^{1}$, T Tousseyn $^{1,2}$, E Van Cutsem ${ }^{3}$, H Prenen $^{3}$, S Tejpar $^{3}$, M Spaepen ${ }^{4}$, G Matthijs ${ }^{4}$, C Decaestecker ${ }^{5,6}$, X Moles Lopez ${ }^{5,7}$, P Demetter ${ }^{7}$, I Salmon ${ }^{5,7}$ and X Sagaert ${ }^{\star, 1,2}$

${ }^{1}$ Translational Cell and Tissue Research Unit, Department of Imaging and Pathology, KU Leuven, Minderbroedersstraat 12 blok $\mathrm{Q}$ bus 1032, 3000 Leuven, Belgium; ${ }^{2}$ Department of Pathology, University Hospitals Leuven, Herestraat 49, Leuven 3000, Belgium; ${ }^{3}$ Digestive Oncology Unit, Department of Oncology, University Hospitals Leuven, Herestraat 49, Leuven 3000, Belgium; ${ }^{4}$ Department of Human Genetics, University Hospitals Leuven, Herestraat 49, Leuven 3000, Belgium; ${ }^{5}$ DIAPath-Center for Microscopy and Molecular Imaging (CMMI), Rue Adrienne Bolland 8, Gosselies 6041, Belgium; ' Laboratories of Image, Signal Processing and Acoustics, Université Libre de Bruxelles, Avenue F.D. Roosevelt 50, Brussels 1050, Belgium and ${ }^{7}$ Department of Pathology, Erasme Hospital, Université Libre de Bruxelles, Route de Lennik 808, Brussels 1070, Belgium

Background: Microsatellite instability (MSI) accounts for 15\% of all colorectal tumours. Several specific clinicopathologicals (e.g., preference for the proximal colon over the distal colon, improved prognosis and altered response to chemotherapeutics) are described for this subset of tumours. This study aimed to analyse morphological, inflammatory and angiogenic features of MSI vs microsatellite stable (MSS) tumours.

Methods: Twenty-seven MSS and 29 MSI, TNM stage matched, colorectal tumours were selected from the archive of the Department of Pathology, UZ Leuven. Morphology was analysed on haematoxylin-eosin sections. Immunohistochemistry for CD3, CD4, CD8, CD20 and CD68 was used to map tumour infiltration in both a digital and traditional microscope-based manner for all distinct morphological components of the tumour. CD31 immunostains were performed to assess angiogenesis.

Results: Morphological tumour heterogeneity was a marked feature of MSI tumours, occurring in 53\% of the cases as compared with $11 \%$ of the MSS tumours $(P<0.001)$. Digital immune quantification showed an increased number of tumour-infiltrating cytotoxic T-lymphocytes $(C D 8+)$ in MSI compared with MSS tumours for both the tumour $(P=0.02)$ and peritumoural area $(P=0.03)$. Traditional microscope-based quantification confirmed these results $(P<0.001$ for both) and, in addition, revealed large numbers of CD68 + macrophages in the peritumoural area of $\mathrm{MSI}$ cancers $(P=0.001)$. Moreover, traditional microscope-based analysis was able to distinguish between lymphocytes directly infiltrating the tumoural glands (intra-epithelial) and those infiltrating only the neoplastic stroma around the glands (intratumoural). Quantification showed high numbers of intra-epithelial CD3 +, CD4 +, CD8 +, CD20 + and CD68 + cells in MSI compared with MSS cancers $(P<0.001, P=0.01, P<0.001, P<0.001$ and $P=0.006$, respectively). Higher microvessel density (MVD) was observed in MSI tumours compared with their MSS counterpart.

Conclusions: Mixed morphology, reflecting tumour heterogeneity, is an important feature of MSI tumours and may have both diagnostic and therapeutic impact. The inflammatory reaction also presented with significant differences in MSI vs MSS colorectal tumours. MSI cancers showed mainly infiltration by cytotoxic T-cells in both the tumour and the close border around the tumour, as well as increased intra-epithelial infiltration in contrast to MSS tumours. The type of immune cell and the compartment it resides in (intratumoural or intra-epithelial) depend both on MSI status and morphology. Finally, MSI tumours showed a higher angiogenic capacity represented by an increased MVD, hinting for possible therapeutic consequences.

*Correspondence: Professor Dr X Sagaert; E-mail: xavier.sagaert@uzleuven.be

Revised 31 March 2015; accepted 15 May 2015; published online 11 June 2015

(c) 2015 Cancer Research UK. All rights reserved 0007-0920/15 
The molecular pathogenesis of colorectal cancer (CRC) is well documented but not yet fully understood. About $94 \%$ of the cases arises sporadically, a small minority of $5 \%$ has a hereditary origin and $1 \%$ can be attributed to chronic inflammatory bowel disease (Crohn's disease, colitis ulcerosa) (Fearon, 2011). Two major pathways are known in the development of colorectal carcinoma: the chromosomal instability (CIN) pathway and the microsatellite instability (MSI) pathway (Fleming et al, 2012; Bogaert and Prenen, 2014). CIN is characterised by DNA aneuploidy and mutations in different proto-oncogenes and tumour-suppressor genes such as adenomatous polyposis coli tumour-suppressor gene, Kirsten-ras (K-ras) proto-oncogene and p53 tumour-suppressor gene and deleted in colon cancer tumour-suppressor gene. This pathway accounts for the majority of sporadic CRCs and for CRCs in the context of Familial Adenomatous Polyposis syndrome (Fearon and Vogelstein, 1990; Salahshor et al, 1999). The MSI pathway, defined as a status of genomic instability due to a deficient DNA mismatch repair (MMR) system, accounts for $10-15 \%$ of sporadic CRCs. The MMR system consists of six proteins (MLH1, MSH2, MSH3, MSH6, PMS1 and PMS2) that interact to recognise and excise mismatches and mutations. Thereby they allow re-synthesis and re-ligation of the strand by DNA-polymerase $\delta$ en DNA-ligase (Ionov et al, 1993; Thibodeau et al, 1993; Alexander et al, 2001; Heinimann, 2013). In case of MMR deficiencies, mostly due to hypermethylation of the MLH1 promotor region (Vilar and Gruber, 2010), the microsatellite repeats located throughout the genome will shorten or lengthen resulting in MSI (Kim et al, 2013). MSI is also associated with CRCs arising in the context of hereditary nonpolyposis CRC, also known as Lynch syndrome. This syndrome is characterised by significantly increased risk of developing colorectal, endometrial and several other cancers due to germ-line mutations in one of the MMR genes (Ionov et al, 1993; Pino and Chung, 2010).

CRCs with MSI are associated with a specific histological, mutational and clinical phenotype. Histologically, MSI tumours often present as more poorly differentiated cancers, with mucinous, signet cell and medullary differentiation frequently observed. In addition, they are typically infiltrated by lymphocytes and accompanied by an often prominent peritumoural Crohn'slike reaction (Shia et al, 2003). Because of the distinct pathogenesis of MSI tumours, they often present with reduced frequencies of APC, TP53 and KRAS mutations and with a higher incidence of transforming growth factor, beta receptor II and BRAF mutations. This altered mutational landscape results in a decreased signalling through the WNT pathway (Cancer Genome Atlas Network, 2012; Donehower et al, 2013). Clinically, this type of tumour is more frequently located proximal to the splenic flexure, has a more favourable prognosis and is less prone to lymph node and distant metastatic spread (Reimers et al, 2013). Furthermore, studies have demonstrated that there was no benefit of addition of 5fluorouracil (5-FU) chemotherapy for stages II and III MSI-H CRCs; a trend towards worse clinical outcome for those receiving 5-FU was even detected (Ribic et al, 2003; Des Guetz et al, 2009). However, other studies could not validate these findings (Sinicrope et al, 2011). It has been suggested that the effects of antiVEGF would also vary according to MSI status (Hansen et al, 2011; Kloor et al, 2014).

In this study, 57 CRCs were analysed with the aim to document in depth the presence of intratumoural heterogeneity, inflammatory reaction and angiogenic features in relation to MSI status.

\section{MATERIALS AND METHODS}

Patient selection. Twenty-nine specimen of CRC with known MSI and 27 cases known to be microsatellite stable (MSS), diagnosed between 2010 and 2013, were selected from the archive of the pathology department of the University Hospitals of Leuven. Patients who underwent preoperative radiotherapy or chemotherapy were excluded from this study (to avoid interference with the quality of immunohistochemistry). Furthermore, MSS cases were matched to MSI tumours for TNM criteria (Seventh edition AJCC/UICC). The diagnosis of CRC was established by histological examination using the World Health Organisation (WHO) criteria. Immunohistochemistry for MLH1, MSH2 and MSH6 was used to determine microsatellite stability status. Absence of one of the MMR proteins in the tumour cells with positivity of the internal control (lymphocytes) was used as criteria for MSI diagnosis. Cases negative for one of the MMR genes by immunohistochemistry were investigated for MSI by multiplex PCR using a validated panel of 10 microsatellite markers (BAT 25, BAT 26, D5S346, D17S250, D2S123, TGFB-RII, BAT40, D18S58, D17S787 and D18S69). Samples were graded as MSI-high when instability was observed in $>30 \%$ of the

\begin{tabular}{|c|c|c|c|}
\hline & MSI & MSS & $P$-value \\
\hline Mean age, years & 67.2 & 70.6 & \\
\hline \multicolumn{4}{|l|}{ Sex } \\
\hline Men & $14 / 29$ & $15 / 27$ & \multirow[t]{2}{*}{$P=0.6050$} \\
\hline Women & $15 / 29$ & $12 / 27$ & \\
\hline \multicolumn{4}{|l|}{ Tumour site } \\
\hline Caecum & $5 / 29$ & $2 / 27$ & \multirow[t]{7}{*}{$P<0.0001^{*}$} \\
\hline Ascending colon & $15 / 29$ & $7 / 27$ & \\
\hline Transverse colon & $6 / 29$ & $3 / 27$ & \\
\hline Descending colon & $1 / 29$ & $4 / 27$ & \\
\hline Sigmoid & $2 / 29$ & $6 / 27$ & \\
\hline Rectum & $3 / 29$ & $5 / 27$ & \\
\hline Proximal to splenic flexure & $27 / 29$ & $12 / 27$ & \\
\hline \multicolumn{4}{|l|}{ Differentiation grade } \\
\hline Well + moderately differentiated & $8 / 29$ & $21 / 27$ & \multirow[t]{2}{*}{$P=0.0002^{\star}$} \\
\hline Poorly differentiated & $21 / 29$ & $6 / 27$ & \\
\hline \multicolumn{4}{|l|}{ Crohn's-like reaction } \\
\hline Strong + moderate & $4 / 29$ & $5 / 27$ & \multirow{3}{*}{$P=0.7265$} \\
\hline Poor + absent & $22 / 29$ & $20 / 27$ & \\
\hline$?$ & $3 / 29$ & $2 / 27$ & \\
\hline \multicolumn{4}{|l|}{ Fibrotic reaction } \\
\hline Strong + moderate & $9 / 29$ & $13 / 27$ & \multirow{3}{*}{$P=0.2640$} \\
\hline Poor + absent & $17 / 29$ & $12 / 27$ & \\
\hline$?$ & $3 / 29$ & $2 / 27$ & \\
\hline \multicolumn{4}{|l|}{$\mathrm{T}$ (tumour) } \\
\hline 1 & $0 / 29$ & $0 / 27$ & \multirow[t]{4}{*}{ NA } \\
\hline 2 & $1 / 29$ & $1 / 27$ & \\
\hline 3 & $15 / 29$ & $17 / 27$ & \\
\hline 4 & $13 / 29$ & $9 / 27$ & \\
\hline \multicolumn{4}{|l|}{ N (lymph nodes) } \\
\hline 0 & $16 / 29$ & $14 / 27$ & \multirow[t]{3}{*}{ NA } \\
\hline 1 & $6 / 29$ & $9 / 27$ & \\
\hline 2 & $7 / 29$ & $4 / 27$ & \\
\hline \multicolumn{4}{|l|}{ M (metastasis) } \\
\hline 0 & $26 / 29$ & $25 / 27$ & \multirow[t]{2}{*}{ NA } \\
\hline 1 & $3 / 29$ & $2 / 27$ & \\
\hline \multicolumn{4}{|l|}{ Postoperative chemotherapy } \\
\hline Yes & $13 / 29$ & $19 / 27$ & \multirow[t]{3}{*}{ NA } \\
\hline No & $16 / 29$ & $7 / 27$ & \\
\hline$?$ & $0 / 29$ & $1 / 27$ & \\
\hline \multicolumn{4}{|l|}{ Recurrence } \\
\hline Yes & $4 / 29$ & $6 / 27$ & \multirow[t]{2}{*}{$P=0.4966$} \\
\hline No & $25 / 29$ & $21 / 27$ & \\
\hline
\end{tabular}

Abbreviations: $\mathrm{MSI}=$ microsatellite instability; MSS = microsatellite stable; NA = not applicable. ${ }^{\star} P<0.05$. 

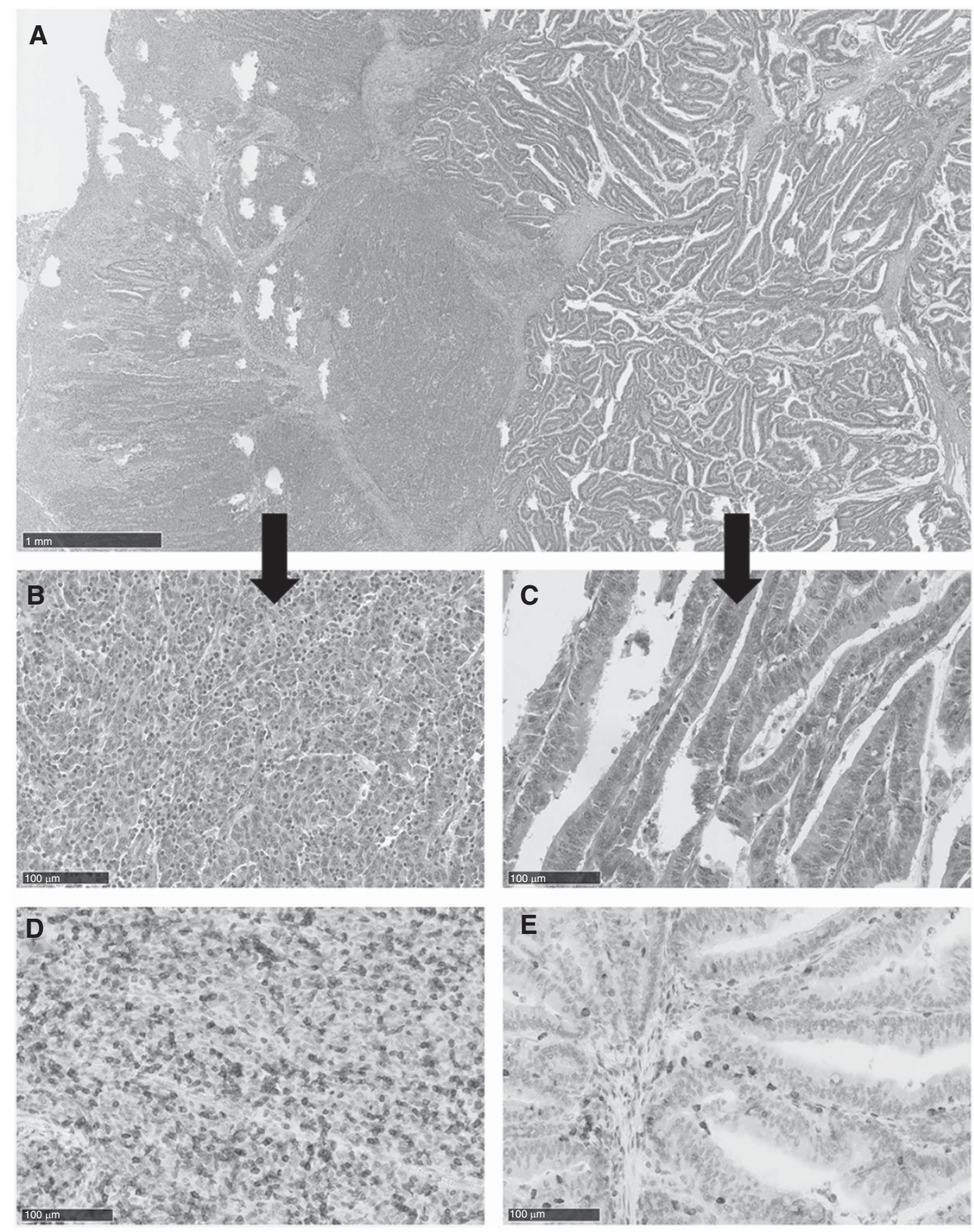

Figure 1. Histologic and inflammatory reaction in MSI tumours. (A) H\&E stain shows that this tumour is composed of a glandular and solid pattern. (B, C) Histology of the glandular and solid pattern in more detail. (D, E) Immunohistochemistry for CD3 shows a combination of intratumoral and intraepithelial lymphocytes in the glandular part of the MSI tumour, while mainly intra-epithelial lymphocytes were found in the solid part of the MSI tumour.

tested microsatellites that conform to the Bethesda guidelines (Umar et al, 2004). Hypermethylation of the MLH1 promoter was determined by MS-MLPA (SALSA MS-MLPA probe mix ME011-B2, MRC-Holland, Amsterdam, the Netherlands). The percentage of hypermethylation was the mean percentage between the Deng C and Deng D region of the MLH1 promoter. Percentages $>15 \%$ were interpreted as positive for the hypermethylation of the MLH1 promoter. The presence of the BRAF V600E mutation was demonstrated by Sanger sequencing.

Immunohistochemistry. Formalin-fixed, paraffin-embedded sections were immunostained for $\mathrm{CD} 3$ (ready-to-use (RTU) rabbit polyclonal anti-human antibodies; Dako, Glostrup, Denmark), CD4, CD8, CD20, CD68, CD31 (RTU mouse monoclonal anti-human antibodies; Dako) and peripheral node addressin (PNAd) clone MECA-79 (1/3000; Biolegend, San Diego, CA, USA). All immunostains were performed on $5-\mu$ m-thick paraffin sections using the Dako autostainer. For visualisation, the Envision Flex system (Dako) was used and antigen retrieval was carried out using the Dako pretreatment module at $\mathrm{pH}=6$. For PNAd, an additional incubation of $30 \mathrm{~min}$ was necessary with a rabbit anti-rat immunoglobuline $(1 / 75+10 \%$ normal human serum, Dako).

Morphological features. Haematoxylin and eosin (H\&E) sections were investigated for different histological features, such as: degree of differentiation, following the WHO criteria based on the percentage of glands in the tumour ( $>95 \%$ good, $50-95 \%$ moderate and $<50 \%$ poor), morphological pattern (glandular, mucinous or solid), fibrotic, and Crohn's-like reaction (absent, poor, moderate or extensive). Tumours were scored as glandular when gland formation was observed in the tumour without excessive mucus production. The tumour was scored as mucinous if $>50 \%$ of the lesion was composed of pools of extracellular mucin containing malignant epithelium. If $<50 \%$ the lesion was 
Table 2. Histological features

\begin{tabular}{|c|c|c|c|c|c|}
\hline \multirow[t]{2}{*}{ Case } & \multicolumn{3}{|c|}{ Primary tumour } & \multicolumn{2}{|c|}{ Lymph node metastasis } \\
\hline & Pattern 1 & Pattern 2 & Pattern 3 & Pattern 1 & Pattern 2 \\
\hline 1 & Solid & Mucinous & Glandular & Glandular & Solid \\
\hline 2 & Solid & Glandular & & Glandular & \\
\hline 3 & Solid & Glandular & & Solid & \\
\hline 4 & Mucinous & Glandular & & Glandular & Mucinous \\
\hline 5 & Solid & Mucinous & Glandular & & \\
\hline 6 & Glandular & Solid & Mucinous & & \\
\hline 7 & Solid & Mucinous & Glandular & Solid & Glandular \\
\hline 8 & Solid & Mucinous & Glandular & Solid & Glandular \\
\hline 9 & Mucinous & Glandular & & & \\
\hline 10 & Glandular & Solid & Mucinous & & \\
\hline 11 & Solid & Glandular & Mucinous & & \\
\hline 12 & Glandular & Mucinous & & & \\
\hline 13 & Solid & Mucinous & & Solid & Mucinous \\
\hline 14 & Mucinous & Glandular & & & \\
\hline 15 & Solid & Glandular & Mucinous & Glandular & \\
\hline 16 & Glandular & Solid & & & \\
\hline
\end{tabular}

composed of mucin, the tumour was defined as a mucin-producing tumour. Solid differentiation was assigned when sheets of malignant cells in the absence of glandular formation were observed. To score morphology, one section per centimetre tumour was investigated with an average of $5 \mathrm{H} \& \mathrm{E}$ slides with tumour per case (ranging from 2 to 15). Furthermore, all resected lymph nodes were checked for tumour metastasis with respect to morphology according to the previous definitions according to WHO criteria.

Immunoscores. Regarding immunohistochemistry, quantification of immune cells was assessed in a digital and traditional microscope-based manner. Only the representative FFPE block per tumour was studied, with one section per stain. For the digital quantification, slides were scanned utilising a digital slide scanner (NanoZoomer 2.0-HT C9600, Hamamatsu Photonics K.K., Hamamatsu city, Japan). Later, the regions of interest of tumour and peritumour, defined as 1-mm border around the tumour, were encircled on the digital images followed by quantification of the percentage of the positive tissue area (labelling index) in each region with the Visiomorph software (Visiopharm, Hoersholm, Denmark) (Verset et al, 2013). For the traditional microscopebased analysis, positive cells were counted in 10 high-power fields $(\mathrm{HPF}, \times 400)$ for the intra-epithelial (immune cells directly infiltrating the neoplastic glands), intratumoural (immune cells only infiltrating the neoplastic stroma surrounding the glands) and peritumoural (1 HPF around the tumour) compartments. The surface area of $1 \mathrm{HPF}$ equals to $0.3025 \mathrm{~mm}^{2}$. Analysis for intra-epithelial and intratumoural compartment was carried out for each morphological pattern individually. The KlintrupMakinen score for the tumour and the invasive margin was determined using the representative H\&E section of each case. Therefore, immune infiltration by lymphocytes, neutrophilic and eosinophilic granulocytes were scored. A score $0,1,2$ or 3 was assigned when respectively absent, weak (Patch-like infiltrate), moderate (band-like infiltrate) or severe increase (very prominent cup-shaped infiltrate) of each cell type was observed in the tumour area or invasive margin. A score 2 or 3 for the invasive margin was only assigned when destruction of cancer islets was observed.

Microvessel density (MVD). Angiogenesis in tumours was evaluated by the CD31 staining: the number of blood vessels in the tumour area was counted and divided by the tumour area with MVD as a result (no. of vessels per $\mathrm{mm}^{2}$ ). Tumour area was measured by a digital micro imaging device (Leica, DMD108, Leica, Wetzlar, Germany).

Statistics. All statistical analyses were performed using the GraphPad Prism 5 software (GraphPad Software, La Jolla, CA, USA) and the Statistica Package (StatSoft, Tulsa, OK, USA). Differences between MSS and unstable tumours were investigated by comparing the cellular count values for each type of cells for different regions in the tumour using the Mann-Whitney $U$-test. The same statistical test was used to compare MVD between both groups. To check the association of MSI status with other categorical variables such as degree of differentiation, tumour heterogeneity, fibrotic reaction and Crohn's-like reaction, contingency tables were designed and statistically compared with Fisher's exact test. $P<0.05$ was used as criterion for significance.

\section{RESULTS}

Clinicopathological characteristics. In total, 56 cases were collected, 29 MSI and 27 MSS tumours matching for TNM stage. The proportions of male and females were equally distributed in each group and the mean age of the patients in the MSI group was 67.2 years, with the youngest patient being 27 years and the oldest patient being 87 years. For the MSS group, the mean age was slightly higher with a mean age of 70.6 years and a range from 50 to 83 years. In the group of MSI tumours, a high predominance for the right colon was observed while MSS tumours were more frequently observed in the left colon $(P=0.0004)$. As MSI and MSS tumours were selected to match for TNM criteria, no statement can be made with respect to this (Table 1). All MSI tumours were scored as MSI high by means of PCR. Eight out of the 29 MSI tumours occurred in the context of Lynch syndrome. Twenty-one MSI tumours arose in sporadic context and presented frequently with BRAFV600E mutations (66.6\%) and variable levels of hypermethylation of the MLH1 promoter (ranging from $21 \%$ to $89 \%$ and an average of $46.5 \%$ ).

Morphological characteristics. In our series of TNM-matched tumours, MSI cancers were significantly less differentiated compared with MSS tumours $(P=0.0005)$. Seventeen MSI tumours presented with a mucinous differentiation and 15 MSI tumours with solid morphology. None of those patterns were common in MSS tumours: the mucinous pattern was observed in only three MSS cases, and solid differentiation was not identified in the MSS group. A more pronounced Crohn's-like reaction $(P=0.72)$ or an altered degree of fibrosis $(P=0.26)$ in MSI tumours compared with MSS cases was not noted.

Tumour heterogeneity in primary tumour and lymph node metastasis. Sixteen of the MSI tumours (55\%) were composed of more than one morphological pattern, with combinations of glandular, mucinous and/or solid differentiation areas (Figure 1). This mixed morphology was observed in only $11 \%$ of the MSS tumours $(P<0.0001)$. Sporadic and Lynch-associated tumours showed similar patterns of morphological heterogeneity, and BRAF mutational status did not affect the occurrence of heterogeneity. The glandular pattern was the most abundant pattern in the cohort of MSI heterogeneous tumours (15 out of 16), followed by mucinous and solid differentiation. Of the 16 MSI cases presenting with morphological heterogeneity, 8 presented with positive lymph nodes. In all but one case of the heterogeneous primary tumours with a component of a glandular growth pattern, the glandular component had metastasised to the lymph nodes. The solid pattern had high metastatic capacity to the lymph nodes in contrast to the mucinous differentiation pattern, which was only associated with 

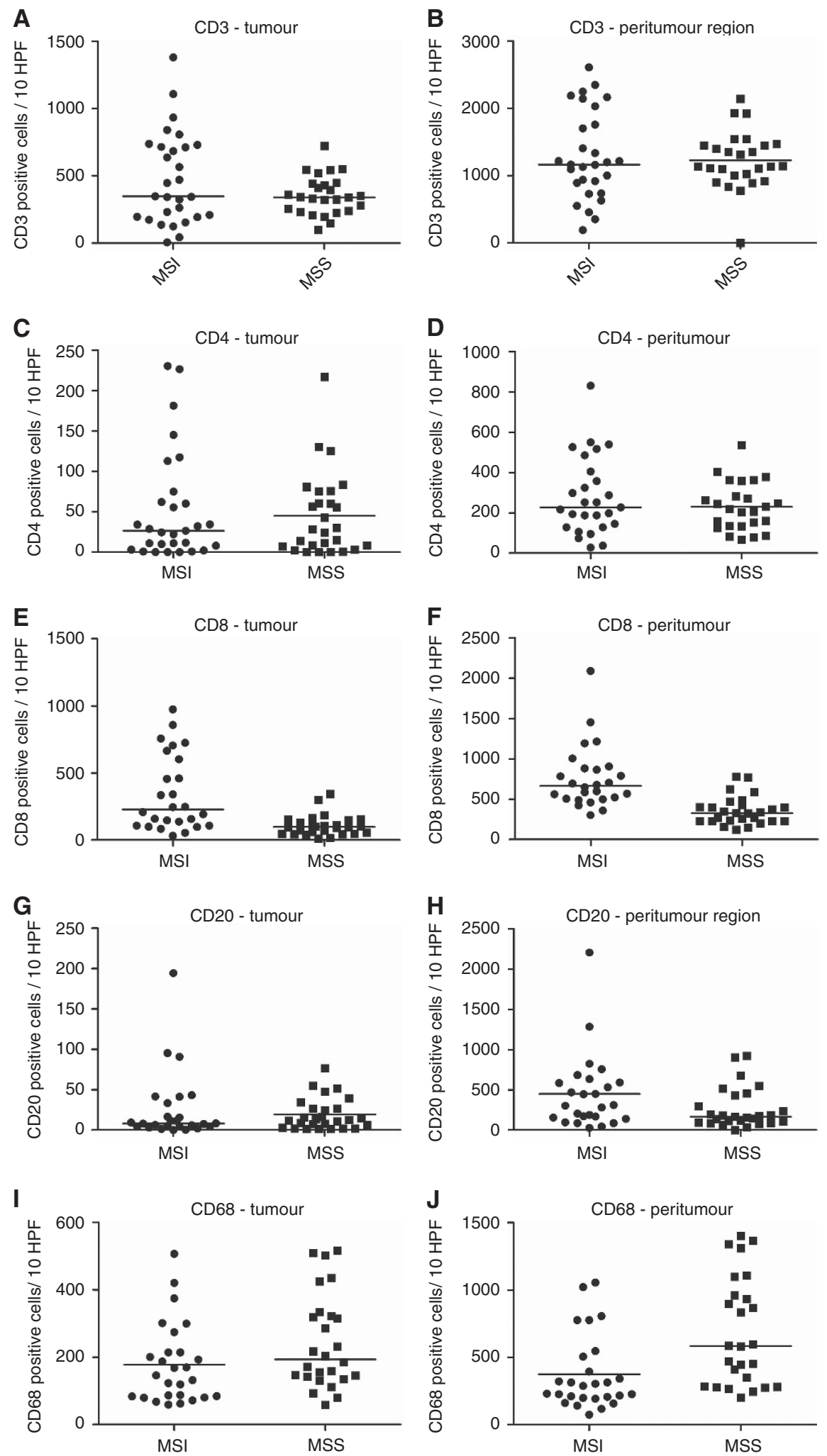

Figure 2. Analogous lymphocyte quantification of MSI and MSS tumours. (A-D) No differences in CD3 + or CD4 + lymphocyte infiltration for the tumoral and peritumoral compartments were observed between MSI and MSS tumours. (E, F) Higher amount of infiltrating cytotoxic lymphocytes $(\mathrm{CD} 8+)$ were observed in the tumoral and peritumoral compartments of MSI compared with MSS cases. (G, H) Similar amounts of CD20 + lymphocytes were quantified in the tumoral and peritumoral compartments of MSI and MSS tumours. (I, J) Macrophages (CD68 +) are enriched in the peritumoral area of MSI compared with MSS tumours; however, these differences were not seen in the tumoral area.

two lymph node metastasis in the MSI group. However, the group of tumours with lymph node metastasis was too small for statistical analysis (Table 2).
Inflammation. Digital immune cell quantification showed increased numbers of tumour-infiltrating cytotoxic T-lymphocytes $(\mathrm{CD} 8+)$ in MSI compared with MSS tumours for both the tumour 
Table 3. Labelling index of the different immune markers for each compartment and obtained by means of digital quantification

\begin{tabular}{|c|c|c|c|c|c|c|c|}
\hline \multirow[b]{2}{*}{$\begin{array}{l}\text { Digital } \\
\text { analysis }\end{array}$} & \multicolumn{7}{|c|}{ Mann-Whitney U-test (*significance at $P<0.05$ ) } \\
\hline & $\begin{array}{l}\text { Median } \\
\text { MSI }\end{array}$ & $\begin{array}{c}\text { Lower quartile } \\
\text { MSI }\end{array}$ & $\begin{array}{c}\text { Upper quartile } \\
\text { MSI }\end{array}$ & $\begin{array}{l}\text { Median } \\
\text { MSS }\end{array}$ & $\begin{array}{c}\text { Lower quartile } \\
\text { MSI }\end{array}$ & $\begin{array}{l}\text { Upper quartile } \\
\text { MSS }\end{array}$ & $\begin{array}{c}2 \times \text { one-sided exact } \\
P\end{array}$ \\
\hline CD3 tumour & 0.043 & 0.014 & 0.090 & 0.020 & 0.016 & 0.037 & 0.06 \\
\hline CD3 peritumour & 0.052 & 0.036 & 0.095 & 0.044 & 0.030 & 0.061 & 0.30 \\
\hline CD4 tumour & 0.001 & 0.000 & 0.005 & 0.001 & 0.000 & 0.004 & 0.45 \\
\hline CD4 peritumour & 0.006 & 0.002 & 0.018 & 0.004 & 0.001 & 0.008 & 0.29 \\
\hline CD8 tumour & 0.016 & 0.007 & 0.051 & 0.005 & 0.005 & 0.013 & $0.02^{*}$ \\
\hline CD8 peritumour & 0.021 & 0.014 & 0.032 & 0.014 & 0.007 & 0.023 & $0.03^{*}$ \\
\hline CD20 tumour & 0.003 & 0.001 & 0.005 & 0.002 & 0.001 & 0.004 & 0.25 \\
\hline $\begin{array}{l}\text { CD20 } \\
\text { peritumour }\end{array}$ & 0.019 & 0.008 & 0.030 & 0.013 & 0.006 & 0.031 & 0.73 \\
\hline CD68 tumour & - & - & - & - & - & & - \\
\hline $\begin{array}{l}\text { CD68 } \\
\text { peritumour }\end{array}$ & - & - & - & - & - & & - \\
\hline
\end{tabular}

$(P=0.02)$ and peritumoural $(1 \mathrm{~mm}$ border around the tumour) regions $(P=0.03)$. Traditional microscope-based analysis confirmed those results $(P<0.001$ for both) (Figure 2). Moreover, digital analysis showed a tendency of higher CD3 + T-cell infiltration in MSI compared with MSS tumours $(P=0.06)$. However, no other differences were found by means of digital analysis for the other lymphocyte markers (Table 3). Immunohistochemistry for CD68 displayed a lot of background signal and was therefore not suitable for digital analysis. In contrast, traditional quantification revealed large numbers of CD68 + macrophages in the tumour $(P=0.05)$ and peritumoural area $(P=0.001)$ of MSS tumours. Importantly, traditional microscope-based quantification allowed to distinguish between lymphocytes directly infiltrating the tumoural glands (intra-epithelial) and those infiltrating the neoplastic stroma around the glands in the tumour region (intratumoural). High numbers of intra-epithelial $\mathrm{CD} 3+$, $\mathrm{CD} 4+, \mathrm{CD} 8+, \mathrm{CD} 20+$ and $\mathrm{CD} 68+$ cells were observed in MSI compared with MSS tumours $P<0.001, P=0.01, P<0.001$, $P<0.001$ and $P=0.006$, respectively). On the contrary, MSS colorectal tumours were characterised by elevated levels of intratumoural $\mathrm{CD} 3+, \mathrm{CD} 20+$ and $\mathrm{CD} 68+$ cells $(P<0.001$, $P=0.04$ and $P=0.009$, respectively; Figure 3, Table 4). Lymphocytes were quantified for all distinct morphologic compartments within one tumour during traditional analysis. Glandular MSI tumours presented with a combination of intratumoural and intraepithelial infiltrating $\mathrm{CD} 3+, \mathrm{CD} 4+, \mathrm{CD} 8+, \mathrm{CD} 20+$ and CD68 + cells while glandular MSS tumours showed mainly intratumoural infiltration of CD3,$+ \mathrm{CD} 20+$ and CD68 + cells. The mucinous compartment showed lower immune infiltration compared with the other morphological components in both MSI and MSS tumours. Solid differentiation was only observed in MSI CRCs and characterised by a high abundance of intra-epithelial $\mathrm{CD} 3+, \mathrm{CD} 4+, \mathrm{CD} 8+, \mathrm{CD} 20+$ and $\mathrm{CD} 68+$ cells compared with the glandular and mucinous differentiation. With respect to the Klintrup-Makinen score, no differences were found in immune infiltration for the tumour and invasive margin in MSI and MSS tumours (Table 5).

Angiogenesis. Microsatellite unstable tumours presented with higher densities of microvessels in comparison to MSS cancers $(P=0.026)$. The median number of blood vessels in MSI cases equals to 7.27 vessels per $\mathrm{mm}^{2}$ with a range from 3.1 to 20.0 vessels per $\mathrm{mm}^{2}$, while MSS tumours presented with a median of 5.98 vessels per $\mathrm{mm}^{2}$ and a range from 2.8 to 16.1 microvessels per $\mathrm{mm}^{2}$
(Figure 4, Table 6). PNAd immunostains demonstrated that no high endothelial venules were present in CRC, neither in MSI or in MSS tumours.

\section{DISCUSSION}

In the present study, we demonstrated that there are major differences between MSI and MSS colorectal tumours that present on the morphological, inflammatory and the angionenic level. Similar to other series, we found that MSI tumours tend to occur in patients of a slightly younger age, with preponderance of the right colon (Sinicrope et al, 2006; Jass, 2007). Previous studies emphasised that MSI tumours show a reduced likelihood towards metastasis in regional lymph nodes and distant organs, resulting in an improved overall and disease-free survival (Gryfe et al, 2000). In this study, we could not validate these findings as our samples were chosen to match for TNM criteria.

Regarding morphology, tumour heterogeneity or polyclonality is the most striking feature that distinguishes MSI from MSS CRCs in our series. More than $50 \%$ of the MSI tumours presented with a combination of two or more morphological patterns such as glandular, mucinous and/or solid, while this was only the case in $11 \%$ of the MSS tumours. In addition, half of the heterogeneous MSI tumours presented with affected lymph nodes, and it was evident that the heterogeneity of the primary tumour was reflected in the lymph node metastasis as heterogeneous lymph node metastasis were observed in the majority (62\%) of the heterogeneous primary tumours. The higher incidence of morphological heterogeneity in MSI compared with MSS tumours may be explained by the mutator phenotype of MSI tumours, resulting in several molecular clones with possible distinct morphological features, a hypothesis that remains to be verified. This observed heterogeneity in MSI tumours may affect both diagnosis and therapeutic approach in daily clinical practise. On the diagnostic level, presence of morphological heterogeneity in a CRC biopsy may be suggestive of MSI and should therefore warrant the pathologist for further MSI testing. On the therapeutic level, it is plausible and even highly likely that distinct morphological components present with a distinct molecular background and that those different morphological clones present with different genetic footprints that form the base these days of individualised therapy. Therefore new studies should investigate whether 

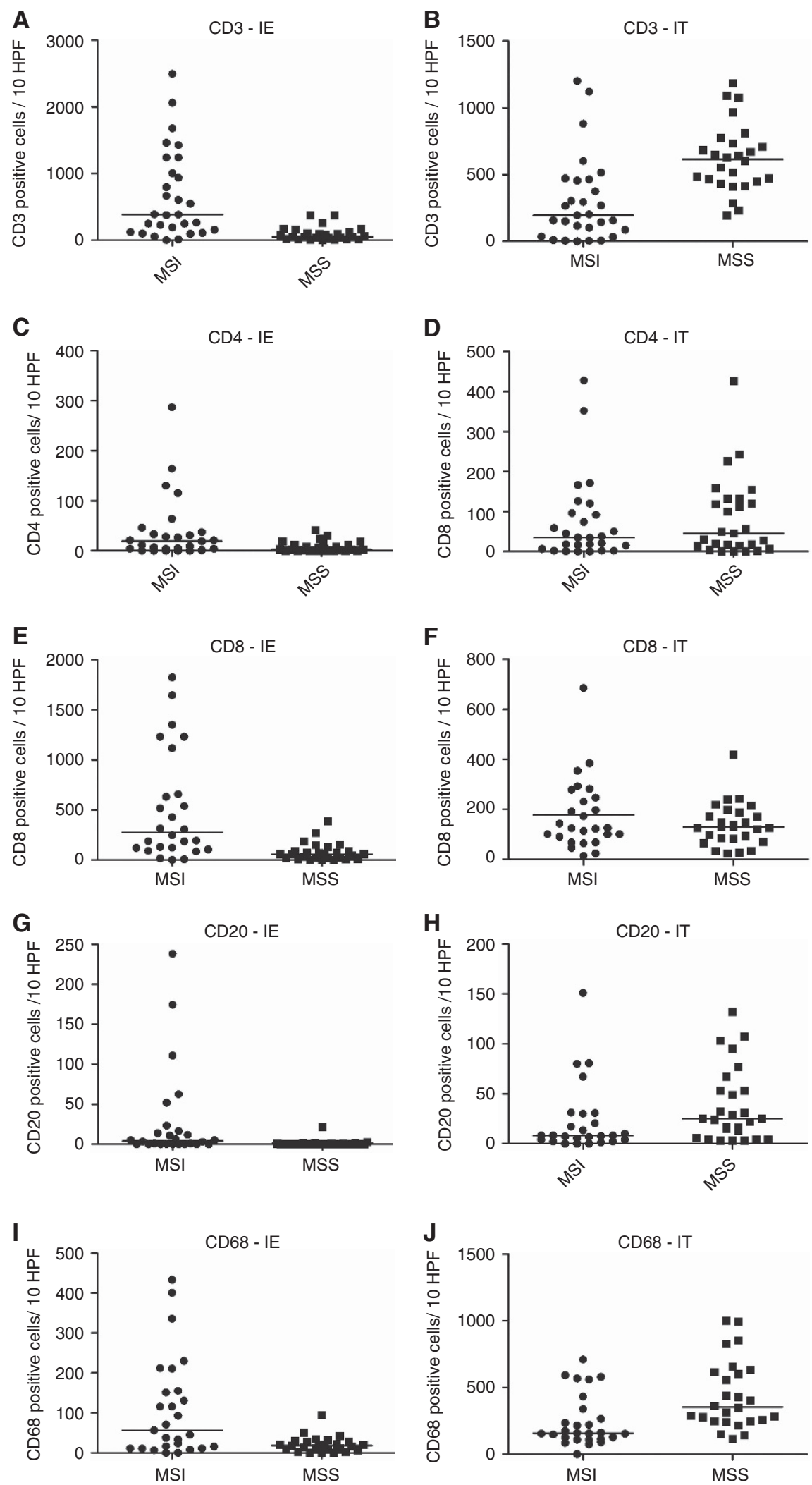

Figure 3. Analogous quantification of immune cells in the intra-epithelial (IE) and intratumoral (IT) compartments of MSI and MSS tumours. (A, C, E, G, I) CD3 + , CD4 + , CD8 +, CD20 + and CD68 + cells are enriched in the IE component of MSI compared with MSS tumours. (B, H, J) However, CD3 +, CD20 + and CD68 + cells are more prevalent in the IT compartment of MSS cases. (D, F) No differences in CD4 + and CD8 + intratumoral lymphocyte infiltration were observed. The horizontal bars in the data distribution indicate medians.

individual morphological components in one tumour present with distinct mutational landscapes and distinct gene expression profiles. Our observations confirm the new concept that it is outdated to consider tumours as one homogeneous biological event and that it is increasingly important for diagnostic, therapeutic and prognostic approaches to recognise that tumours are composed of 
Table 4. Results of analogous quantification of tumour-infiltrating lymphocytes counted in 10 HPF for the distinct compartments

\begin{tabular}{|c|c|c|c|c|c|c|c|}
\hline \multirow[b]{2}{*}{$\begin{array}{l}\text { Analogous } \\
\text { analysis }\end{array}$} & \multicolumn{7}{|c|}{ Mann-Whitney $U$-test (*significance at $P<0.05$ ) } \\
\hline & $\begin{array}{c}\text { Median } \\
\text { MSI }\end{array}$ & $\begin{array}{c}\text { Lower quartile } \\
\text { MSI }\end{array}$ & $\begin{array}{c}\text { Upper quartile } \\
\text { MSI }\end{array}$ & $\begin{array}{c}\text { Median } \\
\text { MSS }\end{array}$ & $\begin{array}{c}\text { Lower quartile } \\
\text { MSS }\end{array}$ & $\begin{array}{c}\text { Upper quartile } \\
\text { MSS }\end{array}$ & $\begin{array}{c}2 \times \text { one-sided } \\
\text { exact } P\end{array}$ \\
\hline CD3 tumour & 350 & 197 & 715 & 341 & 145 & 440 & 0.4088 \\
\hline CD3 peritumour & 1166 & 894 & 1758 & 1140 & 1108 & 1550 & 0.7605 \\
\hline CD3 intra-epithelial & 384 & 157 & 1004 & 51 & 22 & 118 & $<0.0001^{\star}$ \\
\hline CD3 intratumour & 195 & 87 & 456 & 616 & 453 & 728 & $<0.0001^{*}$ \\
\hline CD4 tumour & 27 & 8 & 62 & 29 & 8 & 68 & 1.000 \\
\hline CD4 peritumour & 228 & 138 & 382 & 221 & 136 & 283 & 0.5517 \\
\hline CD4 intra-epithelial & 19 & 4 & 35 & 2.5 & 0 & 12 & $0.0111^{*}$ \\
\hline CD4 intratumour & 35 & 11 & 94 & 45 & 15 & 126 & 0.7098 \\
\hline CD8 tumour & 227 & 115 & 566 & 98 & 52 & 140 & $0.0002^{\star}$ \\
\hline CD8 peritumour & 663 & 512 & 879 & 329 & 231 & 417 & $<0.0001^{\star}$ \\
\hline CD8 intra-epithelial & 267 & 121 & 651 & 59 & 21 & 88 & $<0.0001^{*}$ \\
\hline CD8 intratumour & 126 & 93 & 243 & 130 & 85 & 180 & 0.5452 \\
\hline CD20 tumour & 8 & 4 & 39 & 13 & 5 & 27 & 0.6308 \\
\hline CD20 peritumour & 307 & 160 & 590 & 167 & 100 & 635 & 0.0738 \\
\hline CD20 intra-epithelial & 4 & 0 & 45 & 0 & 0 & 1 & $0.0006^{*}$ \\
\hline CD20 intratumour & 8 & 4 & 31 & 25 & 10 & 53 & $0.0424^{\star}$ \\
\hline CD68 tumour & 132 & 80 & 213 & 194 & 143 & 321 & 0.0503 \\
\hline CD68 peritumour & 287 & 203 & 450 & 584 & 302 & 953 & $0.0010^{*}$ \\
\hline CD68 intra-epithelial & 51 & 11 & 152 & 20 & 10 & 29 & $0.0057^{*}$ \\
\hline CD68 intratumour & 159 & 120 & 302 & 356 & 251 & 611 & $0.0009^{*}$ \\
\hline
\end{tabular}

Table 5. Klintrup-Makinen score for the tumour area and invasion front with respect to MSI status

\begin{tabular}{|l|c|c|c|c|}
\hline & $\begin{array}{c}\text { MSI- } \\
\text { tumour }\end{array}$ & $\begin{array}{c}\text { MSI-invasive } \\
\text { margin }\end{array}$ & $\begin{array}{c}\text { MSS- } \\
\text { tumour }\end{array}$ & $\begin{array}{c}\text { MSS_invasive } \\
\text { margin }\end{array}$ \\
\hline Score 0 & 2 & 5 & 0 & 0 \\
\hline Score 1 & 9 & 16 & 13 & 23 \\
\hline Score 2 & 9 & 6 & 12 & 3 \\
\hline Score 3 & 9 & 2 & 2 & 1 \\
\hline \multicolumn{5}{|l}{ Abbreviations: MSI = microsatellite instability; MSS = microsatellite stable. } \\
\hline
\end{tabular}

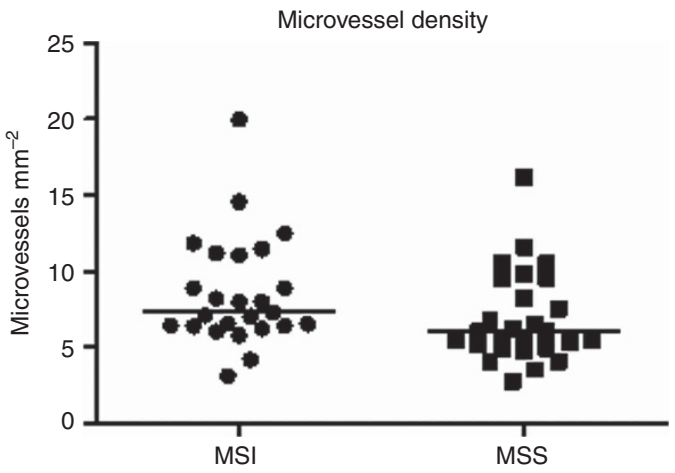

Figure 4. Higher microvessel density was observed in MSI compared with MSS tumours. The horizontal bars in the data distribution indicate medians.

a combination of distinct tumour types. Therefore, all tumour components should be investigated individually to overcome inaccuracies due to the heterogeneous nature of the tumour (Gerlinger et al, 2012; Bedard et al, 2013; Burrell et al, 2013).
Table 6. Bloodvessel count, measurements of tumour area and microvessel density

\begin{tabular}{|l|c|c|c|}
\hline & $\begin{array}{c}\text { Average area } \\
\text { in } \mathbf{~ m m}^{2} \\
\text { (min-max) }\end{array}$ & $\begin{array}{c}\text { Average blood } \\
\text { vessel count } \\
\text { (BVC) (min-max) }\end{array}$ & $\begin{array}{c}\text { Average microvessel } \\
\text { density (in BVC mm } \\
\text { (min-max) }\end{array}$ \\
\hline MSI & $182.3(79.7-421.0)$ & $1502.3(408-2812)$ & $8.5(3.1-20.0)$ \\
\hline MSS & $142.4(55.6-304.8)$ & $959.3(294.0-2053)$ & $7.1(2.8-16.1)$ \\
\hline \multicolumn{2}{|l|}{ Abbreviations: MSI= microsatellite instability; MSS=microsatellite stable. } \\
\hline
\end{tabular}

Furthermore, on the morphologic level, we also found that MSI tumours tend to be more poorly differentiated in comparison to their TNM-matched, MSS counterparts in concordance with known literature. The poorly differentiated display of MSI tumours stems from the fact that MSI tumours often present with mucinous or solid morphology while both morphological patterns are uncommon features in MSS tumours. However, contrary to other studies, no differences in fibrotic and Crohn's-like reaction were observed in our study, indicating that these features are not suitable parameters for the recognition of MSI (Alexander et al, 2001; Buckowitz et al, 2005).

Regarding the inflammatory tumour response, two quantification methods were assessed to analyse and quantify the immune infiltration: digital and traditional microscope-based analysis. Results obtained from both methods were in high accordance as they both showed significant higher levels of cytotoxic T-cells in the tumour and peritumoural region of MSI compared with MSS tumours. This inflammatory pattern may explain the better prognosis for MSI tumours as cytotoxic T-cells supress micrometastasis. (Naito et al, 1998; Guidoboni et al, 2001; Prall et al, 2004; Laghi et al, 2009; Roxburgh et al, 2013; Ling et al, 2014). Furthermore, traditional microscope-based analysis revealed increased intra-epithelial infiltration in MSI tumours for all 
immune cell markers tested, indicating that an interaction between specific MSI-related tumour features and T-cell receptor repertoire allow for lymphocyte invasion into the neoplastic glands and not just the neoplastic stroma. Some advantages of traditional microscope-based quantification are the fact that it is able to distinguish intratumoural- and intra-epithelial-infiltrating immune cells, providing a bulk of extra information. Furthermore, the human eye used in traditional quantification is able to distinct background from authentic positivity, making it possible to quantify tumour-infiltrating macrophages. Disadvantages of the latter method are the fact that it is more prone to inter-observer variability and more time consuming. On the contrary, the advantages of digital quantification are the rather short time frame and objectiveness of counting. Downsides of this technology are difficulties in distinguishing positivity from background signal and the fact that it is not yet possible to subdivide the tumour area into an intra-epithelial and intratumoural compartment without extensive manual interventions or the help of an additional and specific epithelial marker.

In addition to the quantification, analysis of the immune infiltrate shows that lymphocytic infiltration is heterogeneously spread within one tumour. Both the density of lymphocytic infiltration and the compartment the immune cells reside in (intra-epithelial or intratumoural) depend on and highly correlate with the morphological features of the tumour, hence emphasising once more that tumours should be studied and analysed on the clonal level (and that morphological analysis can guide this process) (Figure 1). Mucinous MSI and MSS tumours show barely no lymphocytic infiltration compared with glandular and solid tumours. BRAF mutational status nor Lynch syndrome affected the immune infiltration. In the future, it would be of great interest to investigate these difference in $\mathrm{T}$-cell receptor repertoire for immune cells residing in the intra-epithelial and intratumour compartment individually with respect to morphology to unravel why lymphocytes migrate into the neoplastic glands in MSI tumours.

The Klintrup-Makinen score, which determines the amount of lymphocytes, neutrophilic and eosinophilic granulocytes in the tumour and invasive margin on an H\&E section, could not validate the observations from the digital and traditional microscope-based immunoscores. This can be explained by the fact that the KlintrupMakinen score takes into account the amount of neutrophilic and eosinophilic granulocytes, while this was not the case in our scoring system.

Finally, besides morphological and inflammatory characteristics, the angiogenic features were also compared for MSI and MSS CRCs as angiogenesis can be a favourable or detrimental factor for cancer progression. In our series, MSI tumours showed a significant higher blood vessel density compared with MSS. In an attempt to elucidate the function of the blood vessels in MSI tumours, we performed immunohistochemistry for PNAd, a marker for high endothelial venules (HEV). HEV are composed of plumb cuboidal endothelial cells and are mainly located in secondary lymphoid organs. Their main function is to enable lymphocyte extravasation. Previous reports showed the presence of HEV in solid tumours, including CRC (Martinet et al, 2011). These findings were not validated in our cohort as no HEV were observed in MSI nor MSS tumours. The difference in MVD between MSI and MSS is striking, and it should be investigated whether this has a therapeutic impact in patients treated with antiangiogenic therapy.

In conclusion, we can state that morphological heterogeneity is an important feature of MSI tumours that may reflect the underlying molecular heterogeneity of the tumour, thereby impacting both diagnostic and therapeutic procedures. Additionally, the inflammatory reaction in MSI tumours is also heterogeneous and clone dependent, with a massive amount of (peri)tumour-infiltrating cytotoxic T-lymphocytes, while their number is considerably lower in MSS tumours. Furthermore, immune cells have a higher capacity to migrate into the intraepithelial compartment in MSI tumours that can depend on the interaction of specific tumour characteristics with the T-cell receptor repertoire. Finally, MSI tumours have a higher neoangiogenic capacity represented by the increased MVD in MSI compared with MSS cancers but whether this may represent a therapeutic target remains to be investigated.

\section{ACKNOWLEDGEMENTS}

We thank Gijs Budé, Nathalie Volders, Kathleen Van den Eynde, Sarah Cumps and Emilie Bittoun for their excellent technical assistances. XS is a senior clinical investigator of the FWOVlaanderen (http://www.fwo.be/en/). TT holds a Mandate for Fundamental and Translational Research from the 'Stichting tegen Kanker' (2014-083). This study was also supported by the concerted action grant from the KU Leuven no. 3M040406 (to TT) and the FWO-Vlaanderen. DIAPATH (CMMI) is supported by the European Regional Development Fund, the Walloon Region (Belgium) and the Fonds Yvonne Boël (Brussels, Belgium). CD is a Senior Research Associate with the FNRS.

\section{REFERENCES}

Alexander J, Watanabe T, Wu TT, Rashid A, Li S, Hamilton SR (2001) Histopathological identification of colon cancer with microsatellite instability. Am J Pathol 158: 527-535.

Bedard PL, Hansen AR, Ratain MJ, Siu LL (2013) Tumour heterogeneity in the clinic. Nature 501: 355-364.

Bogaert J, Prenen H (2014) Molecular genetics of colorectal cancer. Ann Gastroenterol 27: 9-14.

Buckowitz A, Knaebel HP, Benner A, Bläker H, Gebert J, Kienle P, Von Knebel Doeberitz M, Kloor M (2005) Microsatellite instability in colorectal cancer is associated with local lymphocyte infiltration and low frequency of distant metastases. Br J Cancer 92: 1746-1753.

Burrell RA, Mcgranahan N, Bartek J, Swanton C (2013) The causes and consequences of genetic heterogeneity in cancer evolution. Nature 501: 338-345.

Des Guetz G, Schischmanoff O, Nicolas P, Perret GY, Morere JF, Uzzan B (2009) Does microsatellite instability predict the efficacy of adjuvant chemotherapy in colorectal cancer? A systematic review with metaanalysis. Eur J Cancer 45: 1890-1896.

Donehower LA, Creighton CJ, Schultz N, Shinbrot E, Chang K, Gunaratne PH, Muzny D, Sander C, Hamilton SR, Gibbs RA, Wheeler D (2013) MLH1silenced and non-silenced subgroups of hypermutated colorectal carcinomas have distinct mutational landscapes. J Pathol 229: 99-110.

Fearon ER (2011) Molecular genetics of colorectal cancer. Annu Rev Pathol 6: 479-507.

Fearon ER, Vogelstein B (1990) A genetic model for colorectal tumorigenesis. Cell 61: 759-767.

Fleming M, Ravula S, Tatishchev SF, Wang HL (2012) Colorectal carcinoma: pathologic aspects. J Gastrointest Oncol 3: 153-173.

Gerlinger M, Rowan AJ, Horswell S, Larkin J, Endesfelder D, Gronroos E, Martinez P, Matthews N, Stewart A, Tarpey P, Varela I, Phillimore B, Begum S, Mcdonald NQ, Butler A, Jones D, Raine K, Latimer C, Santos CR, Nohadani M, Eklund AC, Spencer-Dene B, Clark G, Pickering L, Stamp G, Gore M, Szallasi Z, Downward J, Futreal PA, Swanton C (2012) Intratumor heterogeneity and branched evolution revealed by multiregion sequencing. N Engl J Med 366: 883-892.

Gryfe R, Kim H, Hsieh ET, Aronson MD, Holowaty EJ, Bull SB, Redston M, Gallinger S (2000) Tumor microsatellite instability and clinical outcome in young patients with colorectal cancer. $N$ Engl J Med 342: 69-77.

Guidoboni M, Gafà R, Viel A, Doglioni C, Russo A, Santini A, Del Tin L, Macrì E, Lanza G, Boiocchi M, Dolcetti R (2001) Microsatellite instability 
and high content of activated cytotoxic lymphocytes identify colon cancer patients with a favorable prognosis. Am J Pathol 159: 297-304.

Hansen TF, Jensen LH, Spindler KL, Lindebjerg J, Brandslund I, Jakobsen A (2011) The relationship between serum vascular endothelial growth factor A and microsatellite instability in colorectal cancer. Colorectal Dis 13: 984-988.

Heinimann K (2013) Toward a molecular classification of colorectal cancer: the role of microsatellite instability status. Front Oncol 3: 272.

Ionov Y, Peinado MA, Malkhosyan S, Shibata D, Perucho M (1993) Ubiquitous somatic mutations in simple repeated sequences reveal a new mechanism for colonic carcinogenesis. Nature 363: 558-561.

Jass JR (2007) Classification of colorectal cancer based on correlation of clinical, morphological and molecular features. Histopathology 50: 113-130.

Kim TM, Laird PW, Park PJ (2013) The landscape of microsatellite instability in colorectal and endometrial cancer genomes. Cell 155: 858-868.

Kloor M, Staffa L, Ahadova A, Von Knebel Doeberitz M (2014) Clinical significance of microsatellite instability in colorectal cancer. Langenbecks Arch Surg 399: 23-31.

Laghi L, Bianchi P, Miranda E, Balladore E, Pacetti V, Grizzi F, Allavena P, Torri V, Repici A, Santoro A, Mantovani A, Roncalli M, Malesci A (2009) $\mathrm{CD} 3+$ cells at the invasive margin of deeply invading (pT3-T4) colorectal cancer and risk of post-surgical metastasis: a longitudinal study. Lancet Oncol 10: 877-884.

Ling A, Edin S, Wikberg ML, Öberg Å, Palmqvist R (2014) The intratumoural subsite and relation of CD8(+) and FOXP3 $(+)$ T lymphocytes in colorectal cancer provide important prognostic clues. Br J Cancer 110: 2551-2559.

Martinet L, Garrido I, Filleron T, Le Guellec S, Bellard E, Fournie JJ, Rochaix P, Girard JP (2011) Human solid tumors contain high endothelial venules: association with T- and B-lymphocyte infiltration and favorable prognosis in breast cancer. Cancer Res 71: 5678-5687.

Naito Y, Saito K, Shiiba K, Ohuchi A, Saigenji K, Nagura H, Ohtani H (1998) $\mathrm{CD} 8+\mathrm{T}$ cells infiltrated within cancer cell nests as a prognostic factor in human colorectal cancer. Cancer Res 58: 3491-3494.

Cancer Genome Atlas Network (2012) Comprehensive molecular characterization of human colon and rectal cancer. Nature 487: 330-337.

Pino MS, Chung DC (2010) Application of molecular diagnostics for the detection of Lynch syndrome. Expert Rev Mol Diagn 10: 651-665.

Prall F, Dührkop T, Weirich V, Ostwald C, Lenz P, Nizze H, Barten M (2004) Prognostic role of CD8 + tumor-infiltrating lymphocytes in stage III colorectal cancer with and without microsatellite instability. Hum Pathol 35: 808-816.

Reimers MS, Zeestraten EC, Kuppen PJ, Liefers GJ, Van De Velde CJ (2013) Biomarkers in precision therapy in colorectal cancer. Gastroenterol Rep (Oxf) 1: 166-183.

Ribic CM, Sargent DJ, Moore MJ, Thibodeau SN, French AJ, Goldberg RM, Hamilton SR, Laurent-Puig P, Gryfe R, Shepherd LE, Tu D, Redston M,
Gallinger S (2003) Tumor microsatellite-instability status as a predictor of benefit from fluorouracil-based adjuvant chemotherapy for colon cancer. N Engl J Med 349: 247-257.

Roxburgh CS, Richards CH, Macdonald AI, Powell AG, Mcglynn LM, Mcmillan DC, Horgan PG, Edwards J, Shiels PG (2013) The in situ local immune response, tumour senescence and proliferation in colorectal cancer. Br J Cancer 109: 2207-2216.

Salahshor S, Kressner U, Pâhlman L, Glimelius B, Lindmark G, Lindblom A (1999) Colorectal cancer with and without microsatellite instability involves different genes. Genes Chromosomes Cancer 26: 247-252.

Shia J, Ellis NA, Paty PB, Nash GM, Qin J, Offit K, Zhang XM, Markowitz AJ, Nafa K, Guillem JG, Wong WD, Gerald WL, Klimstra DS (2003) Value of histopathology in predicting microsatellite instability in hereditary nonpolyposis colorectal cancer and sporadic colorectal cancer. Am J Surg Pathol 27: 1407-1417.

Sinicrope FA, Foster NR, Thibodeau SN, Marsoni S, Monges G, Labianca R, Kim GP, Yothers G, Allegra C, Moore MJ, Gallinger S, Sargent DJ (2011) DNA mismatch repair status and colon cancer recurrence and survival in clinical trials of 5-fluorouracil-based adjuvant therapy. J Natl Cancer Inst 103: 863-875.

Sinicrope FA, Rego RL, Halling KC, Foster N, Sargent DJ, La Plant B, French AJ, Laurie JA, Goldberg RM, Thibodeau SN, Witzig TE (2006) Prognostic impact of microsatellite instability and DNA ploidy in human colon carcinoma patients. Gastroenterology 131: 729-737.

Thibodeau SN, Bren G, Schaid D (1993) Microsatellite instability in cancer of the proximal colon. Science 260: 816-819.

Umar A, Boland CR, Terdiman JP, Syngal S, De La Chapelle A, Rüschoff J, Fishel R, Lindor NM, Burgart LJ, Hamelin R, Hamilton SR, Hiatt RA, Jass J, Lindblom A, Lynch HT, Peltomaki P, Ramsey SD, Rodriguez-Bigas MA, Vasen HF, Hawk ET, Barrett JC, Freedman AN, Srivastava S (2004) Revised Bethesda Guidelines for hereditary nonpolyposis colorectal cancer (Lynch syndrome) and microsatellite instability. J Natl Cancer Inst 96: 261-268.

Verset L, Tommelein J, Moles Lopez X, Decaestecker C, Mareel M, Bracke M, Salmon I, De Wever O, Demetter P (2013) Epithelial expression of FHL2 is negatively associated with metastasis-free and overall survival in colorectal cancer. Br J Cancer 109: 114-120.

Vilar E, Gruber SB (2010) Microsatellite instability in colorectal cancer-the stable evidence. Nat Rev Clin Oncol 7: 153-162.

This work is published under the standard license to publish agreement. After 12 months the work will become freely available and the license terms will switch to a Creative Commons AttributionNonCommercial-Share Alike 4.0 Unported License 